\title{
STUDY OF ORGANOPHOSPHOROUS POISONING CASES AT MAHARAJAH INSTITUTE OF MEDICAL SCIENCES, A.P.
}

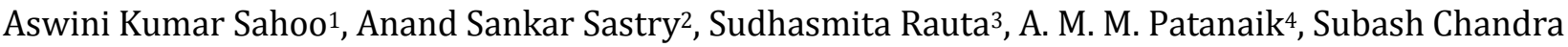
Mahapatra $^{5}$

\section{HOW TO CITE THIS ARTICLE:}

Aswini Kumar Sahoo, Anand Sankar Sastry, Sudhasmita Rauta, A. M. M. Patanaik, Subash Chandra Mahapatra. "Study of Organophosphorous Poisoning Cases at Maharajah Institute of Medical Sciences, A.P". Journal of Evolution of Medical and Dental Sciences 2014; Vol. 3, Issue 35, August 14; Page: 9201-9206,

DOI: $10.14260 /$ jemds/2014/3187

ABSTRACT: BACKGROUND \& OBJECTIVES: Organophosphorus pesticide self-poisoning is a major clinical and public-health problem across much of rural Asia. The aim of this study was to analyze the patterns, the social factors and the clinical outcomes of OP poisoning at the Maharajah Institute Of Medical Sciences, Vizianagaram. MATERIALS AND METHODS: Fifty organophosphorous poisoning cases who were admitted to the MIMS, during the period of 1year (May 2013to June 2014), were studied. RESULTS: Fifty cases of OP poisoning were studied. In the present study, 56\% cases were males, with the highest number of cases in the age group of 21 to 30 years (44\%). Sixty four \% belonged to married category. Sixty \% of organophosphorous poisoning victims belonged to the farming community. Chlorpyrifos was consumed by $58 \%$ of the victims. $64 \%$ of the OP poisoning victims were having family problems. Muscarinic and nicotinic symptoms were prevalent in majority of victims. $64 \%$ people had recovery and Intermediate syndrome was observed in 36\% cases of organophosphorous poisoning. CONCLUSION: There was a high incidence of OP poisoning related mortality in this region. The OP compounds were readily available at low costs in the market. A time of stress and frustration can lead to their use as a common poison to commit suicide with.

KEYWORDS: Intermediate Syndrome; Insecticide; Organophosphorous; Poisoning; Suicide.

INTRODUCTION: The insecticides which have been developed to protect crops are now themselves, causing significant morbidity and mortality by means of environmental pollution and acute poisoning. Organophosphorus insecticides are one of the most predominant insecticides used today. Over forty registered brands of insecticides contain organophosphorus chemicals. ${ }^{1}$ Acute poisoning is an important clinical emergency and a contributor to morbidity and mortality. Nearly one million people are affected globally every year. ${ }^{2}$

World-wide it is estimated that every year tens of millions of people experience symptoms of acute poisoning, more than 3 million people develop serious poisonings because of $1,000,000$ unintentional poisonings and 2,000,000 intentional poisonings. ${ }^{3}$ Organophosphorus (OP) pesticide self-poisoning is a major clinical and public-health problem across much of rural Asia.3,4 of the estimated 5,00000 deaths from self- harm in the region each year, about $60 \%$ are due to pesticide poisoning.4,5 Many studies estimate that organophosphorus pesticides are responsible for around two- thirds of these deaths a total of 200000 a year. 4,6

Deaths from unintentional organophosphorus poisoning are less common than those from intentional poisoning 6 and seem to be more common in regions where highly toxic organophosphorus pesticides (WHO Class I toxicity) are available.7,8 Although extensive data is available regarding the pattern of OP poisoning in India, there is only little information regarding the 


\section{ORIGINAL ARTICLE}

victim profiles and the factors which influence mortality in southern India. The present study aimed to analyze the patterns, the social factors and the clinical outcomes of OP poisoning in this region.

MATERIALS AND METHODS: Fifty organophosphorous poisoning cases who were admitted to the MIMS, during the period of 4 years (May 2013 to June 2014), were studied. The Study includes age and sex profile, type of organophosphorous compound consumed, incidence of intermediate Syndrome in organophosphorous poisoning, the circumstances leading to Poisoning. Correlate the study with other studies.

Diagnosis of organo-phosphorus poisoning: 10 by History, Symptoms and Signs of poisoning, effect of atropine. Management of acute organophosphorus poisoning:9,10 Supportive measures: Oral suction of secretions, maintenance of circulation and establishment of respiration, Prevention of absorption: Adsorbant Cathartics stomach wash, Specific antidote like Atropine and Oximes. Respiratory insufficiency is the commonest cause of death. Hence, positive pressure ventilation should be given if the patient develops signs of respiratory failure.

Unless the patient is comatosed, convulsion or has lost the gag reflex stomach wash should be initiated. Activated charcoal functions as an adsorbent and was given within 4 hours of ingestion. If gastric emptying is delayed it may be useful for up to 12 hours after ingestion. It is the most valuable single agent for emergency management of oral drug poisoning.9,10,11,12 Treatment of complications: Seizures, Pulmonary edema, Pneumonia, Acute respiratory distress syndrome (ARDS), Renal failure, Hypotension, shock, arrhythmias are all managed as per protocol.

RESULTS AND OBSERVATIONS: Fifty cases of OP poisoning were studied. In the present study, 56\% cases were males, with the highest number of cases in the age group of 21 to 30 years (44\%). 64\% were married. $60 \%$ of organophosphorous poisoning victims belonged to the farming community. Chlorpyrifos was consumed by $58 \%$ of the victims. $64 \%$ of the OP poisoning victims were having family problems.

Muscarinic and nicotinic symptoms were prevalent in majority of victims $64 \%$ people had recovery and Intermediate syndrome was observed in 36\% cases of organophosphorous poisoning. The circumstances of poisoning most commonly amongst organophosphorous poisoning victims was suicidal, followed by accidental. The most common motive for committing suicide was family problems and psychiatric illness (Table No. 1)

The majority of organophosphorus poisoning victims suffered from muscarinic and nicotinic symptoms like nausea and vomiting (78\%), muscular weakness (80\%) and excessive sweating in $(68 \%)$ of cases. Neurological involvement in the form of altered sensorium observed in (22\%) of cases, as (Table No. 2). Intermediate syndrome was observed in 18 amongst 50 cases of organophosphorous poisoning, (the Table No. 3). It was observed in our study that, 32 out of 50 organophosphorous poisoning victims reported to our hospital had survived while 18 cases had expired, (Table No. 4)

\begin{tabular}{|l|l|}
\hline Family Problems & $23(63.89 \%)$ \\
\hline Psychiatric Illness & $06(16.67 \%)$ \\
\hline Physical Illness & $03(8.33 \%)$ \\
\hline Motive Unknown & $04(11.11 \%)$ \\
\hline \multicolumn{2}{|c|}{ Table No. 1} \\
\hline
\end{tabular}




\section{ORIGINAL ARTICLE}

\begin{tabular}{|l|c|}
\hline \multicolumn{1}{|c|}{ Clinical Features } & \% age of Cases (\%) \\
\hline Nausea and Vomiting & $39(78 \%)$ \\
\hline Muscular Weakness & $40(80 \%)$ \\
\hline Excessive Sweating & $34(68 \%)$ \\
\hline Altered Sensorium & $11(22 \%)$ \\
\hline Diarrhoea & $21(42 \%)$ \\
\hline
\end{tabular}

Table No. 2: Distribution of clinical features

\begin{tabular}{|c|c|}
\hline $\begin{array}{c}\text { Intermediate } \\
\text { syndrome }\end{array}$ & Cases \\
\hline Present & $18(36 \%)$ \\
\hline Absent & $32(64 \%)$ \\
\hline \multicolumn{2}{|c|}{$\begin{array}{c}\text { Table No. 3: Development of } \\
\text { intermediate syndrome }(\mathrm{n}=50)\end{array}$} \\
\hline
\end{tabular}

\begin{tabular}{|c|c|}
\hline Outcome & Cases \\
\hline Survived & $32(64 \%)$ \\
\hline Died & $18(36 \%)$ \\
\hline
\end{tabular}

Table No. 4 Outcome $(\mathrm{n}=50)$

DISCUSSION: Rise in poisoning is a global phenomenon seen in all age groups and all strata of people. It has enormous medical, legal and social significance. This increase in the incidence of poisoning in recent times is due to stress related to academics in children, job related to adults and loss of social security in old people. The use of poison agent depends on the availability and accessibility of the agent to an individual. Organophosphates continue to be the most commonly used insecticides in southern and western part of the country because of its easy availability and low cost. ${ }^{13}$

The age group with a maximum incidence of intentional self-poisoning was between 21 - 30 years and showed a significant decrease in the extremes of age. The high incidence in the above age group is in accordance with the trends observed nationally and globally. ${ }^{14}$ It is obviously due to the fact that this age group is the determining factor of the life in terms of studies, service, marriage and other life settlement factors. Therefore, they are subjected to the substantial amount of mental stress during this period.

Prevalence of males was more in our study when compared to females, corroborating with other studies. 20 Male preponderance in this study could be accounted to the fact that males are more often exposed to the stress in day to day life, as well as to the occupational hazards than the females in this part of the world. Percentage of organophosphorous poisoning among married people was higher, which is in concurrence with other studies. ${ }^{14,15,16}$ 


\section{ORIGINAL ARTICLE}

In the present study, the victims who were more prone to the OP poisoning were farmers, students and manual labourers which correlated with the findings of Jamanagar study. ${ }^{17}$ It was observed in our study that OP poisoning occurred mainly during the day, which is in agreement with the other study. ${ }^{18}$ Highest number of victims consumed chlorpyriphos in contrast to dizinon the observations was made by Singh et al. ${ }^{19}$ which reflects the importance of difference in availability of poisonous agents from area to area.

Most of the poisoning cases took place in the victims own home. High incidence at home can be attributed to the preference of the victims for a confined home environment. The circumstances of poisoning most common amongst organophosphorous posisoning victims was suicidal, followed by accidental. Generally suicidal poisoning forms a bulk of the total acute poisoning victims, which is not only a phenomenon restricted to India but also a global one..$^{20,21,22}$

This greater incidence of suicide by poisoning is linked to a widespread belief that poisoning kills without much suffering. Human life is full of mental as well as physical stress. Physiological stress factors such as hormonal variations, etc., peer pressure, self-esteem, confusion, self-doubt, expectations, pressure to succeed, academic responsibilities, maladjustment, financial uncertainty and physical diseases are some of the factors contributing to this stress during different age groups. Suicide is often a spontaneous act resulting from the inability to cope with their environment and adjust with the stress they are exposed to. If the emotional support and understanding is not provided, one may resort to suicide as an easy wayout to ones problem and stress.

The most common motive for committing suicide was family problems followed by psychiatric illness. In the 21st century, we live in so much of competitive atmosphere which increasing the stress day by day. The factors are related to finance, domestic problem, emotional problem like failure in love or examination phobia, etc. Majority of organophosphorus poisoning victims suffered from muscarinic and nicotinic symptoms like nausea and vomiting. The same findings were observed by Vishwanath et al. ${ }^{23}$ Comparatively high mortality (18 cases out of 50 ) rate in our study can be attributed to the nature of poison consumed (organophosphorous) which is highly toxic and since it was a referral center most of the patients were referred from the periphery on detection of complications.

CONCLUSION: Education amongst the farmers using organophosphorus compounds regarding its proper manner of use and stringent laws in relation to its use as insecticides and pesticides is the burning need of the time to save the most commonly affected group by these toxic compounds.

\section{REFERENCES:}

1. Reigart J, Routt, Roberts JR. Recognition and management of pesticide poisonings.5th ed. Washington DC: US Environmental Protection Agency; 1999.p.126.

2. Arun M, Nagesh KR, Palimar V, Mohanty MK. Geriatric Poisoning Fatalities: A Manipal Perspective. Medico-legal Update 2005; 5(1): 1-3.

3. Jeyaratnam J. Acute pesticide poisoning: a major global health problem. World Health Stat Q 1990; 43: 139-44.

4. Eddleston M, Phillips MR. Self-poisoning with pesticides. Br Med J 2004; 328: 42-4.

5. Gunnell D, Eddleston M, Phillips MR, Konradsen F. The Global Distribution of fatal pesticide selfpoisoning: Systematic review. BMC Public Health 2007; 7: 357. 


\section{ORIGINAL ARTICLE}

6. Eddleston M. Patterns and problems of deliberate self-poisoning in the developing world. Q J Med 2000; 93: 715-31.

7. McConnell R, Hruska AJ. An epidemic of pesticide poisoning in Nicaragua: implications for prevention in developing countries. Am J Public Health 1993; 83:1559-62.

8. Rosenthal E. The tragedy of Tauccamarca: a human rights perspective on the pesticide poisoning deaths of 4 children in the Peruvian Andes. Int J Occup Environ Health 2003; 9: 5358.

9. Jhon B, Sullivan Jr, Gary R. Hazardous materials toxicology. Baltimore: Williams \& Wilkins; 1992. p.146.

10. Namba T, Nolte CT, Jackrel J, Grob D. Poisoning due to OP insecticides. Am J Med. 1971; 50: 475 $-492$.

11. Nouira S, Abroug F, Elatrous S, Boujdaria R, Bouchoucha S. Prognostic value of serum cholinesterase in OP poisoning. Chest. 1994: 106: $1811-1814$.

12. Koelle GB. Hand book of experimental pharmacology. Berlin: Springer Verlag 1963. p. 9891027.

13. Kumar TS, Kanchan T, Yoganarasimha K, Kumar GP. Profile of unnatural deaths in Manipal, Southern India, 1994-2004. J Clin Forensic Med 2006; 13 (3): 117-120.

14. Aggarwal S, Aggarwal P. Trends of poisoning in Delhi, J Indian Acad Forensic Med.1998; 20 (2): 32-35.

15. Gnyp L, Lewandowska-Stanek H. The analysis of the OP poisoning cases which were treated at the centre for acute poisoning at the Lubin Provincial Hospital in 1994-1996. Przegl Lek. 1997; 54 (10): 734-6.

16. Kamath PG, Dalgi AJ, Patel BM. Diazinon poisoning, JAPI. 1964; 14: 477-81.

17. Gupta BD, Vaghela PC. The profile of fatal poisoning in and around Jamnagar. J Ind Acad Forensic Med. 2005; 27 (3): 145-8.

18. Ingianna Herrero R. Comparative study of cases of poisoningby OP insecticides in various regions of Costa-Rica, Rex, Bio-Trop, 1983, 31 (1): 139-44.

19. Singh S, Balkrishan, Malhotra V. Parathion poisoning in Punjab. JAPI. 1969; 17: 181-87.

20. Chaterjee S.C. Poisoning with organic phosphate insecticides, JIMA. 1967; 48 (4): 153-57.

21. Gannur DG, Prakash M, Reddy KSN. OP compound poisoning in Gulbarga region - A five year study, Ind J Forensic Med Toxicology. 2008; 2 (1): 3-11.

22. Gupta B. OP -facts and myths, medicine update, 1999, 1345-48.

23. Vishwanathan M, Srinivasan K. Poisoning by Bug poison, J Ind Acad Med. 1962; 39 (7): 345-49. 


\section{ORIGINAL ARTICLE}

\section{AUTHORS:}

1. Aswini Kumar Sahoo

2. Anand Sankar Sastry

3. Sudhasmita Rauta

4. A. M. M. Patanaik

5. Subash Chandra Mahapatra

\section{PARTICULARS OF CONTRIBUTORS:}

1. Associate Professor, Department of Medicine, Maharajah Institute of Medical Sciences.

2. Assistant Professor, Department of Medicine, Maharajah Institute of Medical Sciences.

3. Assistant Professor, Department of Pathology, Maharajah Institute of Medical Sciences.

4. Associate Professor, Department of FMT, Maharajah Institute of Medical Sciences.

5. Professor and HOD, Department of Medicine, Maharajah Institute of Medical Sciences.

\section{NAME ADDRESS EMAIL ID OF THE} CORRESPONDING AUTHOR:

Dr. Aswini Kumar Sahoo, Associate Professor, Department of Medicine, MIMS, Nelimarla,

Vizianagaram-535217.

Email: sahoo.aswini@gmail.com

Date of Submission: 12/07/2014.

Date of Peer Review: 14/07/2014.

Date of Acceptance: 06/08/2014.

Date of Publishing: 12/08/2014. 